\title{
A SIMPLIFICAÇÃO DA LINGUAGEM JURÍDICA COMO INSTRUMENTO FUNDAMENTAL DE ACESSO À JUSTIÇA
}

\author{
THE SIMPLIFICATION OF THE JURIDICAL \\ LANGUAGE AS A FUNDAMENTAL INSTRUMENT OF \\ ACCESS TO THE JUSTICE
}

\author{
Luciana Helena Palermo de Almeida Guimarães*
}

\section{RESUMO}

Este artigo apresenta uma análise da linguagem jurídica numa perspectiva linguística, sob a ótica do século XXI. Tal linguagem revela-se um excelente campo para estudo: seu tradicionalismo, a pouca preocupação em ser entendida por aqueles que não pertencem a seu universo e a possibilidade de se elaborar textos forenses com linguagem clara, precisa, livre do verniz erudito ainda tão presente no meio jurídico, sem ignorar o vocabulário técnico deste. A metodologia utilizada para a elaboração desta análise foi a pesquisa bibliográfica, em livros, periódicos e sítios eletrônicos, visto que ela oferece subsídios para a fundamentação teórica e também permite que um tema seja analisado sob novo enfoque, gerando novas conclusões. O que se defende neste trabalho é a importância da inteligibilidade textual, com o objetivo de melhorar consideravelmente a relação entre o Direito e o cidadão comum, facilitando assim o acesso dele à Justiça.

Palavras-chave: Linguagem jurídica. Juridiquês. Justiça.

\begin{abstract}
This article presents an analysis of the juridical language in a linguistic perspective, under the glance of the XXI Century. Such language reveals itself as an excellent field of study: its traditionalism, little concern about being understood by those who do not belong to its universe and the possibility of preparing forensic texts with clear and precise language, free of the erudite varnish still so presented in the juridical area, without ignoring its technical vocabulary. The methodology applied to elaborate this analysis was the bibliographic research, in books, journals and sites, since it offers subsidies to the theoretical substantiation and also allows that a topic can be analyzed in a new focus, thus generating new conclusions. The importance of the textual intelligibility is supported in this work, aiming to improve considerably the relationship between Law and the common citizen, therefore facilitating his access to the Justice.
\end{abstract}

Keywords: Juridical language. Simplification. Justice.

\footnotetext{
* Ma. Professora Universitária no ISCA Faculdades - Instituto Superior de Ciências Aplicadas - Limeira/SP. E-mail: <lhpag@yahoo.com.br>
} 


\section{Introdução}

"Comecemos por dizer que a linguagem é, ao mesmo tempo, efeito e condição do pensamento", segundo Delacroix. Para o jurista Nascimento (2010, p. 3), a linguagem é efeito por traduzir com palavras e fixar o pensamento; é condição porque quanto maior for o conhecimento de palavras, mais claro é o pensamento.

Segundo a obra Ensaio sobre a Origem da Linguagem (1772), de autoria do filósofo e escritor alemão Johann Gottfried von Herder,

[...] a linguagem não é apenas um instrumento de comunicação, mas também o próprio pensamento do ato. $\mathrm{O}$ conhecimento não se separa da forma linguística em que se expressa, e por isso a linguagem também constitui o limite, ainda que móvel, do pensamento. A linguagem não se organiza apenas segundo princípios racionais. As palavras irradiam a capacidade de comunicação para os domínios mais amplos da vida e das forças que a integram, modificam-na e a expressam. (HELDER apud BIDERMAN, 2001, p. 125)

Conforme Edward Sapir (1949) - linguista e antropólogo que concentrou seus esforços na filologia alemã - citado por Gonçalves (2006, p. 1.703), a linguagem chega a ser o meio de expressão de uma sociedade, a tal ponto que o mundo real é "[...] inconscientemente construído sobre os hábitos de linguagem do grupo [...]”.

De acordo com Bakhtin (1979), a linguagem conjetura-se como um processo realizado de forma coletiva, no qual sujeitos de uma determinada sociedade ou grupo social criam e recriam, historicamente, um sistema de significados articulado e visão de mundo, através da interação verbal. Petri (2008) afirma que a língua funciona como um elemento de interação entre o indivíduo e a sociedade em que ele atua. E é por meio dela que a realidade se transforma em signos, com a associação de significantes sonoros a significados, pelos quais a comunicação linguística se processa.

Nunes (2006) nos mostra que o Direito e a linguagem se confundem. É por meio da linguagem escrita e falada que os conhecimentos doutrinários são absorvidos; que os pronunciamentos judiciais são publicados na imprensa oficial e os atos e termos processuais são realizados. Freitas (2008) destaca que a Ciência Jurídica produziu uma linguagem específica, científica e técnica como resultado de seu próprio desenvolvimento, pois instrumentaliza e permite ao operador do Direito, além de seu uso correto, alcançar o verdadeiro sentido das normas jurídicas. Estamos falando do juridiquês, definido por doutrinadores, a exemplo de Arrudão (2007), como o uso de um português ininteligível, através de palavras de raciocínio labiríntico e expressões pedantes, ou seja, que se expressa exibindo conhecimento que realmente não possui. Todavia, sabemos que na área forense existem termos próprios que na verdade não passam a carga semântica desejada quando traduzidos. "Há uma linguagem do Direito porque o Direito dá um sentido particular a certos termos. O conjunto desses termos forma o vocabulário jurídico." (PETRI, 2008, p. 29).

A atividade jurídica tem o cidadão como destinatário e permeia todos os setores da sociedade. Ao lembrarmos que a intenção da linguagem, jurídica ou não, é comunicar algo, devemos nos lembrar da necessidade de adequá-la a esse cidadão, que deseja ter acesso à Justiça, mas precisa entender como decidem os magistrados, a fim de que possa interagir de forma mais segura no cumprimento de seus deveres e na exigência de seus direitos.

Neste estudo pretende-se estabelecer a simplificação da linguagem jurídica como instrumento fundamental para o acesso à Justiça, bem como seus benefícios e os recursos que devem ser utilizados para alcançá-la.

\section{A importância da linguagem na área do direito}

$\mathrm{Na}$ área do Direito, escrever corretamente assume valores maiores que em outros setores da sociedade. A linguagem é o meio utilizado para transmitir ideias, e quanto melhor ela for, melhor será a transmissão. No campo jurídico, tal transmissão precisa ser perfeita para alcançar seus objetivos, obter Justiça.

No campo forense, busca-se convencer, persuadir, legislar, debater e, principalmente, julgar as condutas de outros membros do grupo. Portanto, o uso linguístico necessita ter o seu poder e o seu papel reconhecidos nessa área, pois, para Gnerre (1998, p. 5), 
A linguagem não é usada somente para veicular informações, isto é, a função referencial da linguagem não é senão uma entre outras; entre estas ocupa uma posição central, a função de comunicar ao ouvinte a posição que o falante ocupa de fato ou acha que ocupa na sociedade em que vive. As pessoas falam para serem ouvidas, às vezes respeitadas e também para exercer alguma influência no ambiente em que realizam seus atos linguísticos.

Citamos também aqui a tese de Bobbio (1999, p. 135), que eleva a jurisprudência à categoria de ciência, para demonstrar a importância da linguagem na área do Direito. Segundo tal teoria, o “[...] jurista não observa fatos, mas estuda o significado de determinadas palavras por meio das quais deve reconstruir os fatos". Dessa maneira, seu objeto de estudo é a análise da linguagem do legislador. Assim, esta se coloca como expressão da realidade, por meio de afirmações e negações compostas por orações.

O Direito e seus operadores não falam só para si. Falam para uma audiência mais ampla, a sociedade. Por isso, utilizam uma linguagem pública, que deve ser acessível a todos. O domínio da linguagem jurídica apenas por um grupo é um fato de posse. Entretanto, ela não é fixa, evolui, é prática. Ela está a serviço do Direito. Se o Direito é para todos, sua linguagem também!

Finalizamos com o pensamento do ilustre jurista Luís Roberto Barroso (2007), que se encaixa perfeitamente na proposta deste trabalho: "O Direito é a alternativa que o mundo concebeu contra a força bruta. Em lugar de guerras ou duelos, debates públicos; em vez de armas, ideias e argumentos".

\section{A palavra como ferramenta do direito}

O Direito nos é apresentado por meio da palavra, sua ferramenta funcional, manifestada em todos os sentidos: nas leis, pareceres, razões, sentenças, acórdãos e em outras formas diversas de atos judiciais que não dispensam seu uso para o conhecimento da matéria jurídica. Ainda de acordo com o jurista Nascimento (2010), a expressão lógica, breve, clara e precisa é qualidade da linguagem jurídica escrita. O conjunto desses atributos dá-lhe a elegantia júris, como denomina Von Ihering na obra Espírito do Direito Romano (1943), ou beleza funcional; ou, também, estética funcional. Assim, a complexidade da linguagem não pode ser admitida à ciência que analisa e rege as relações sociais, que disciplina a conduta das pessoas, e que tem por objetivo primordial auxiliar na resolução de conflitos de interesse que nascem no seio de uma sociedade.

O mais importante num texto jurídico não é a beleza da sofisticação da linguagem, mas sim a clareza, a concisão e precisão que ele apresenta, organizado com raciocínio lógico e coerência, originários de uma seleção atenta de fatos relevantes que compõem o caso. Linguagem clara, portanto, é aquela que apresenta alto nível de qualidade, sem omissão de palavras ou sem uso de signos que sejam compreendidos somente por um determinado grupo de pessoas. Entretanto, quando primamos pela simplificação da linguagem jurídica, não estamos defendendo a vulgarização dela, nem estimulando o desuso de termos técnicos necessários ao contexto forense, mas sim, combatendo os excessos que podem facilitar o entendimento do cidadão, ficando mais acessível para todos. Portanto, a simplificação da linguagem jurídica deve ser vista como um instrumento fundamental que oportuniza o acesso à Justiça e contribui, efetivamente, para a atuação do Poder Judiciário como um todo.

Destacamos ainda que escrever bem não é escrever muito. A prolixidade é considerada um defeito e não uma qualidade. Quando um texto é simples, sem ser vulgar; elegante, sem ser pedante; com um acervo de palavras e expressões contextualizadas, sem ser arcaico; ele será respeitado, admirado e recomendado por um simples motivo: é convincente e seguro. Até mesmo o atual presidente dos Estados Unidos, Barack Obama, manifestou-se sobre esse assunto, dizendo que "não entende porque não é possível se fazer um simples termo de adesão de cartão de crédito de apenas uma página". (SIEGEL, 2010).

Nas palavras do desembargador aposentado do Tribunal de Justiça de São Paulo, Alexandre Moreira Germano (2005), a tendência moderna é de redações bem escritas, porém simplificadas e objetivas, que não abusam da linguagem empolada, tampouco dos termos jurídicos. Não se pode fazer literatura, mas, sim, facilitar a leitura do processo. Afinal, o processo deve ter o sentido de resolver um conflito entre duas partes, sem grandes divagações literárias. O magistrado também recomenda que não se utilizem termos em latim ou outros idiomas que 
não sejam o vernáculo, pois não os acha necessários e defende que o português supre todas as exigências do texto.

Embora possamos considerar que a linguagem jurídica não tenha nascido no seio da sociedade, não podemos negar que foi justamente para a sociedade que o Direito foi criado. Postamos aqui para reflexão as palavras de Hegel, filósofo alemão: "Quem exagera no argumento, prejudica a causa" (PIZZINGA, 2008).

Há, portanto, uma parceria essencial entre o Direito e a linguagem, que constituem um par indissociável. Sem a qualidade da segunda, o primeiro não cumpre o seu papel. Leis são feitas com palavras. O jurista não lida diretamente com os fatos, mas com palavras que denotam ou pretendem denotar esses fatos. Em vista do exposto, em toda profissão a palavra pode ser útil, e até mesmo necessária. Mas, na área do Direito, ela é indispensável e imprescindível. Como muito bem dito pelo jurista italiano Carnelutti, "nossas ferramentas não são mais que palavras" (KASPARY, 2003).

\section{A argumentação pela palavra}

Dominar a comunicação em todos os níveis é essencial para o profissional do Direito, visto que sua ferramenta de trabalho, a palavra, se exteriorizada com eficiência, tem o poder de convencer, persuadir e influenciar as pessoas. Tal ação é uma forma de exercer poder sobre os outros, estimulando-os a ver o mundo por uma nova ótica.

O meio jurídico é o da argumentação pela palavra. É com ela que se constroem teses ou refutações, faz-se justiça. O pensamento argumentativo está sempre presente no discurso forense, visto que o conflito entre as partes contrárias exige uma sustentação lógica, a qual, por sua vez, será analisada pelo juiz, que terá de fundamentar sua decisão.

Dessa maneira, o texto jurídico bem elaborado e com forte argumento convence o leitor, devido ao fato de que a argumentação é produzida fazendo uso de técnicas discursivas, de elementos que, na língua, têm o propósito de convencimento.

De acordo com Perelman e Tyteca (2005, p. 252), “[...] a argumentação solicitando uma adesão é antes de tudo uma ação". Por isso, são necessários os seguintes requisitos para alcançarmos a finalidade de persuadir o leitor a respeito das ideias apresentadas: conhecimento mais amplo possível do assunto tratado no texto, dos recursos de linguagem, do próprio leitor, e a seleção dos argumentos que vão ser utilizados. Além disso, jamais se deve perder o foco para quem se está escrevendo, para que se possa produzir um texto bem elaborado, com as solicitações expressas com clareza e argumentação bem construída.

A essência da lei é ordenar, vetar, permitir e punir. O texto jurídico deve ser adequado para solucionar conflitos e não para causá-los, como acontece quando uma norma, ou apenas uma parte dela, é mal redigida.

\section{O juridiquês}

Conforme Mendonça (1987, p. 12), a forma clássica do "dizer jurídico" é a seguinte: “[...] são palavras comuns, com significados incomuns para o leigo; palavras e expressões arcaicas ou latinas, jargão, gíria profissional, termos formais ou com significação elástica ou, ainda, a redundância como tentativa de atingir extrema precisão".

O professor de Direito Penal Felix Valois, em texto escrito na apresentação da obra Constituição Para Todos, de Ronie Stone (1998, p. 1), declara que o senso comum elegeu há muito tempo a linguagem jurídica como arrevesada $e$ confusa, e que, nessa concepção, ela só perderia para o economês. O ilustre docente prossegue relatando que: "[...] do legislador ao mais humilde rábula, passando por tribunais, juízes, doutrinadores, promotores e advogados, todos se esforçam para complicar a palavra, na injustificável ilusão de que falar difícil os torna mais importantes."

Atualmente alguns profissionais do Direito têm direcionado sua atenção para a questão das normas jurídicas escritas em uma linguagem "opaca", impenetrável, o que tem gerado muitos debates, vários textos, obras acadêmicas em geral, com o intuito de se repensar as relações entre Direito e linguagem. Neles se percebe a reprovação dos autores à falta de clareza, concisão e precisão e ao pedantismo, que são utilizados por alguns legisladores ao elaborarem as leis, códigos etc.

É fato que algumas peças jurídicas são redigidas de maneira que é impossível a alguém que não 
seja parte do meio jurídico compreendê-las. Esse estilo rebuscado, denominado juridiquês, impede qualquer possibilidade de conhecimento, ao invés de permitir a compreensão sobre o assunto tratado. Partilha da mesma opinião Gérman Bidart Campos (apud CÁRCOVA, 1998, p. 37), ao afirmar que:

[...] há normas tão complicadas, tão mal redigidas, tão confusas, de tanta exuberância regulamentarista, de técnica tão deficiente, que até os especialistas da mais alta qualidade e perícia quebram a cabeça para entender o que o autor quis dizer. Como então querer que o comum das pessoas as conheça, as compreenda e as cumpra!

O jurisconsulto Eliasar Rosa é outro profissional do Direito que defende uma linguagem mais clara e menos rebuscada nos textos "jurídicos". Ele afirma que:

Em verdade, não é a correção a primeira ou maior virtude do estilo. A clareza é que o é, não apenas para o advogado, mas para todos, pois que a linguagem é o meio geral de comunicação, seu fim supremo. Daí por que, quanto mais clara for, mais útil e eficaz ela será para preencher sua finalidade. Quem é obscuro manifesta, desde logo, ou o desejo de não ser facilmente compreendido, ou a inaptidão para se comunicar. (ROSA, 2003 apud SOUZA, 2011, p. 27).

Mais uma citação que também vai ao encontro das ideias defendidas por Bidart Campos e Rosa é de autoria do advogado Kaspary (2003, p. 2), presente no texto eletrônico "Linguagem do Direito":

O que se critica, e com razão, é o rebuscamento gratuito, oco, balofo, expediente muitas vezes providencial para disfarçar a pobreza das ideias e a inconsistência dos argumentos. O Direito deve sempre ser expresso num idioma bem-feito; conceitualmente preciso, formalmente elegante, discreto e funcional. A arte do jurista é declarar cristalinamente o Direito.

Pode-se deduzir, então, que a linguagem jurídica, em várias situações, não está alcançando o objetivo básico de toda e qualquer forma de linguagem: a comunicação. A maneira excessivamente culta que alguns profissionais insistem em utilizar só agrada a dois tipos de pessoas: a quem dela faz uso e a quem não entende nada, mas acha tudo muito bonito. $\mathrm{E}$, o pior de tudo, a linguagem jurídica está repleta de seguidores dessa forma de "expressão", já que não podemos chamá-la de comunicação. Para os estudiosos da área, isso não deixa de ser uma estratégia, pois utilizam uma linguagem de difícil compreensão a fim de que ela não possa ser compreendida por "leigos". (MENDONÇA, 1987, p. 11).

Não se pode esquecer que uma linguagem carente de atualização afasta o orador de seu público, geralmente formado por pessoas que têm afinidade com a linguagem jurídica, mas também por outras que não dominam esse "jargão profissional". E isso torna essa linguagem, impressa no discurso, ineficaz. Por esse motivo, Schnaid (1998, p. 299, grifo do autor) afirma que: "A eficácia de um discurso depende não só do orador, mas também em grande parte do auditório, no qual se pretende influir (convencer). A comunicação exige uma 'linguagem comum', baseada em símbolos que expressem a mesma coisa para um e outro".

Como resistência ao juridiquês, a tendência contemporânea é que os textos, e também a própria linguagem utilizada para expressar ideias da área forense, apresentem cada vez menos termos técnicos, a fim de tornar mais acessível o entendimento dos trâmites da Justiça. Movimentos em prol da simplificação da referida linguagem ganham cada vez mais espaço no cenário internacional. Não é uma iniciativa recente, visto que desde o final dos anos 70 eles têm surgido nos Estados Unidos e na Inglaterra, originários de operadores do Direito, políticos e da própria sociedade civil, para fazer com que informações importantes na relação entre cidadãos, governos e a sociedade em geral sejam expostas de forma cada vez mais precisa e clara. Aqui no Brasil, tais movimentos ainda são tímidos. Registramos o lançamento, em 2005, da "Campanha pela Simplificação do Juridiquês”, promovida pela Associação dos Magistrados Brasileiros. Segundo ela, advogados, procuradores, promotores de justiça, juízes, professores e acadêmicos devem produzir peças judiciais e trabalhos científicos com frases menos rebuscadas, mas sem comprometer o raciocínio jurídico. Porém, ainda não notamos uma mobilização capaz de ocasionar mudanças concretas. Mas acreditamos que chegar a essas mudanças é apenas uma questão de tempo, pois o crescimento econômico do nosso país e do nível de instrução do povo brasileiro fará com que as exigências de acesso à informação 
em linguagem clara e precisa estejam na pauta das discussões do poder público e da sociedade civil em breve. Haverá o consenso de que a simplificação da linguagem jurídica trará benefícios a todos os envolvidos nesse processo.

\section{O latim como idioma auxiliar da ciência jurídica}

Assim como ocorre em outros setores do conhecimento, o Direito possui uma linguagem particular, específica, com palavras e expressões que encerram significações próprias. Quanto à sua origem, o uso do latim no meio jurídico se deve à sua raiz no Direito Romano da Antiguidade, codificado pelo francês Dionísio Godofredo, em 1538, responsável por editar o Corpus Juris Civilis, conjunto das obras do Direito e leis romanas, organizado por ordem do Imperador Justiniano. No caso do Brasil, o Direito Romano influenciou o Direito Português, ambos trazidos para o nosso país através das ordenações.

Em qualquer obra ligada ao Direito encontramos frases, palavras ou expressões em latim. Assim, o uso de expressões latinas no campo jurídico apresenta objetivos diversos: demonstrar erudição e apego à tradição, impressionar o leitor, entre outros. Porém, o latim leva os operadores do Direito a experimentar resultados indesejáveis, com erros de grafia e de concordância, muitas vezes por completo desconhecimento gramatical desse idioma, especialmente em virtude da eliminação do ensino da língua latina nos cursos de Direito em nosso país.

$\mathrm{Na}$ área jurídica o latim é indispensável, pois mantém relação de dependência com expressões indicativas de institutos próprios, que são, conforme Silva (2001, p. 487), “[...] conjuntos de regras e princípios jurídicos que regem certas entidades ou certas situações de direito". Não nos restam dúvidas de que o latim é um idioma auxiliar da Ciência Jurídica. Todavia, as expressões latinas devem ser usadas no Direito com parcimônia, bom-senso e moderação, dependendo do tipo de destinatário dos textos jurídicos em que elas se inserem, sempre em destaque, com o uso de aspas, itálico ou negrito. Conforme muito bem dito pelo processualista José Carlos Barbosa Moreira (2001, p. 257), “[...] o uso do Latim, entretanto, constitui terreno minado, onde com frequência são vítimas de acidentes os que a ele se lançam sem equipamento necessário".

\section{A redação oficial e a linguagem}

No serviço público, somente atos que estejam expressamente previstos em lei podem ser praticados. Por essa razão, a redação oficial é elaborada sempre em nome desse serviço e em atendimento ao interesse geral dos cidadãos. A redação dos textos legais deve seguir, basicamente, as recomendações expostas na Lei Complementar n. 95, de 26 de fevereiro de 1998, que ditou normas gerais e estabeleceu padrões para a elaboração, a redação, a alteração e a consolidação da legislação federal. Essa lei foi alterada pela Lei Complementar n. 107, de 26 de abril de 2001, em cumprimento ao disposto no parágrafo único do art. 59 da Constituição Federal.

$\mathrm{O}$ art. 11, caput, da referida lei determina que a redação do texto legal se paute pela "clareza, precisão e ordem lógica". Há ainda que se observar na redação legislativa: a clareza, que torna o texto inteligível; a precisão, que complementa a clareza; a coerência, que implica a exposição de ideias bem elaboradas, que tratam do mesmo tema do início ao fim do texto em sequência lógica e ordenada; a concisão, alcançada quando se apresenta a ideia com o mínimo de palavras possível, uso de frases breves, eliminação dos vocábulos desnecessários e substituição de palavras e termos longos por outros mais curtos; e finalmente a consistência, decorrente do emprego do mesmo padrão e do mesmo estilo na redação do texto, o que evita a contradição ou dubiedade entre as ideias expostas.

Quem comunica é sempre o Serviço Público; o que se comunica é sempre algum assunto relativo às atribuições do órgão que faz a comunicação; o destinatário dessa comunicação ou é o público, o conjunto dos cidadãos, ou outro órgão público, do Executivo ou dos outros Poderes da União. Por isso, há necessidade de que o texto legal possa ser lido e compreendido pelo maior número possível de pessoas.

Facilitar o entendimento dos textos legislativos é uma maneira de aproximar a população e favorecer o cumprimento das leis e a aplicação de sanções, caso tais leis não sejam cumpridas, diminuindo assim esforços desnecessários em outra instância, inclusive dos Poderes Executivo e Judiciário. 
Não se concebe um ato normativo redigido de forma obscura, que dificulte ou impossibilite sua compreensão. A transparência do sentido dos atos normativos, bem como sua inteligibilidade, são requisitos do próprio Estado de Direito: é inaceitável que um texto legal não seja entendido pelos cidadãos. As comunicações que partem dos órgãos públicos federais devem ser compreendidas por todo e qualquer cidadão brasileiro. Se a administração federal é única, as comunicações que expede devem seguir o mesmo padrão.

\section{O uso da linguagem jurídica}

O Direito é uma ciência que mantém uma relação muito próxima das suas tradições. Como exemplo disso tem-se a insistência de alguns operadores em manter um vocabulário excessivamente rebuscado, repleto de termos técnicos e que atrapalha o andamento de um processo. Tal atitude dificulta muito o entendimento e afasta do universo jurídico uma grande parcela do povo brasileiro, cujo grau de escolaridade é precário. Uma linguagem com terminologias tão técnicas não contribui, em nada, para a aplicabilidade da Justiça. Mas, infelizmente, algumas pessoas acreditam que isso seja demonstração de um patamar cultural superior e, às vezes, esse tipo de linguagem com excesso de rebuscamento se torna incompreensível até para profissionais da área.

Sendo o Direito uma ciência que trata das normas obrigatórias, das leis que disciplinam as relações dos homens na sociedade, deveria utilizar-se de um vocabulário acessível a todos, sem exibicionismos ou vaidades; e não fazer uso de uma linguagem tão técnica, própria, hermética. É fato que usar termos antiquados, obsoletos não é uma demonstração de sabedoria, mas da falta dela. Como muito bem dito pelo poeta Thiago de Mello, "falar difícil é fácil. O difícil é falar fácil" (MAIA, 2010). Assim, no modo de se escrever no campo jurídico existe uma precaução em adaptar a linguagem e adorná-la de maneira que ela se transforme em um código, cuja decodificação é possível apenas ao pequeno grupo que compõe esse universo.

A linguagem deve ser usada para socializar o conhecimento, e não como manifestação de poder, como instrumento pelo qual se afasta da discussão as pessoas que não possuem condições de decodificá-la.
Para aqueles que não demonstram nenhum compromisso com a democratização do acesso à Justiça, é realmente interessante que o universo jurídico continue falando apenas para si mesmo.

\section{O ato comunicativo jurídico}

$\mathrm{O}$ ato comunicativo jurídico não utiliza a linguagem apenas enquanto língua, mas também, e principalmente, a utiliza como discurso. Tal ato exige a construção de uma fala que seja capaz de convencer o julgador a respeito da veracidade do "real" que se pretende provar. Em virtude disso, a linguagem jurídica vale-se dos princípios da lógica clássica para organização do pensamento. Segundo São Tomás de Aquino, "lógica é a arte de pensar em ordem, facilmente e sem erros". E sem a lógica, a linguagem jurídica não atingiria seu objetivo principal: argumentar para convencer. Por isso, para o operador do Direito é fundamental pensar de forma lógica, encontrar ideias e organizá-las, para que possa escrever bem.

O Direito é uma ciência que rege a conduta das pessoas, valendo-se de uma linguagem prescritiva e descritiva. Desse modo, quando há interesses em conflito ou uma ação humana fere os valores da norma jurídica, exigindo reparação dos mesmos, surge a lide, criando a polêmica na relação entre os interlocutores do processo. Nesse confronto, a linguagem torna-se mais persuasiva por objetivar o convencimento do julgador, que, por sua vez, acautela-se da forma de sua decisão, explicando os mecanismos racionais pelos quais decide na motivação da sentença.

\section{Análise da linguagem jurídica}

Ao analisarmos a linguagem jurídica como um todo, percebe-se que esta ainda é definida por alguns doutrinadores como intangível, intocável, visto que o vocabulário utilizado no exercício da atividade jurisdicional é apresentado com peculiaridades, com termos que só são utilizados por ela. Em virtude disso, há a falsa ideia de que para falar bem devemos falar difícil. Assim, quem se expressa de forma prolixa e rebuscada é considerado mais culto, inteligente e digno de maior respeito; e procura se diferenciar do grupo de incultos que 
utiliza um estilo informal, mas se afasta do destinatário, o povo. Esquece, porém, que as sentenças jurídicas não são destinadas somente aos especialistas. Esquece também que o bom advogado é avaliado pelos argumentos que utiliza e pela qualidade de persuasão com que os torna convincentes, e não pela sofisticação de sua linguagem. A atividade jurídica, como já dito, tem o cidadão como destinatário. A partir do momento em que uma das partes não consegue compreender a mensagem, o intuito da comunicação falhou. É fato que o uso de uma linguagem mais viva, mais dinâmica, menos obscura, mais precisa e compreensível não desrespeita de maneira alguma as normas do Direito como ciência, e sim facilita a vida, o acesso à Justiça do indivíduo leigo, pois usa um repertório comum entre as partes, objeto de atenção de muitos operadores do Direito nas últimas décadas.

A língua é um código social, de caráter mutável, que sofre alterações constantes. Se os indivíduos mudam, a língua também o faz. E essa imutabilidade, segundo a Linguística, comprova a natureza e a essência da linguagem. Afirma o linguista americano Steven Fischer, em entrevista para a revista Veja, de 5 de abril de 2000:

Idiomas não são pedras, mas esponjas. Não se deve tentar impedir o enriquecimento do idioma. É assim que as línguas sobrevivem, mudando continuamente. As transformações sofridas pelo português brasileiro são uma prova de sua força, não da sua fraqueza. (SALGADO, 2000, p. 14).

Machado de Assis (1997, p. 37), que dispensa apresentações, já abordava o problema da língua e sua expressão:

Não há dúvida de que as línguas se aumentam e alteram com o tempo e as necessidades dos usos e costumes. Querer que a nossa pare no século de quinhentos, é um erro igual ao de afirmar que a sua transplantação para a América não lhe inseriu riquezas novas. A este respeito a influência do povo é decisiva. Há, portanto, certos modos de dizer, locuções novas, que de força entram no domínio do estilo e ganham direito de cidade. Mas se isto é verdadeiro o princípio que dele se deduz, não me parece aceitável a opinião que admite todas as alterações da linguagem, ainda aqueles que destroem as leis da sintaxe e a essencial pureza do idioma. A influência popular tem um limite, e o escritor não está obrigado a receber e dar curso a tudo o que o abuso, o capricho e a moda inventaram e fazem correr. Pelo contrário, ele exerce também uma grande parte de influência a este respeito, depurando a linguagem do povo e aperfeiçoando-lhe a razão [...] Escrever como Azurara ou Fernando Mendes seria hoje um anacronismo intolerável. Cada tempo tem seu estilo. Mas estudar-lhes as formas mais apuradas da linguagem, desentranhar deles mil riquezas, que, à força de velhas e fazem novas -, não me parece que se deva desprezar. Nem tudo tinham os antigos, nem tudo tem os modernos; com os haveres de uns e outros é que se enriquece o pecúlio comum.

É lógico que a utilização de vocábulos que estão em desuso e de construções sintáticas típicas do século XIX - períodos exageradamente extensos, repletos de vírgulas e pontos-e-vírgulas - prejudica a compreensão do homem comum contemporâneo, quando ele consulta um texto legal. Lembramos isso aos muitos operadores do Direito que ainda redigem suas peças jurídicas dessa maneira, demonstrando resistência à linguagem atual, insistindo em manter o vocabulário e o latinismo apresentados em textos de outras épocas, sem deixar de mencionar aqui a vaidade que cerca alguns deles.

Ao fazermos uma retrospectiva a respeito da linguagem jurídica, percebemos que, não obstante todo avanço da tecnologia e mudanças na nossa língua materna, a linguagem forense permanece com os mesmos termos técnicos, e o acesso à Justiça encontra aqui uma barreira substancial numa relação linguística que envolve polos dessemelhantes e dissonantes. Podemos afirmar, portanto, que seu processo de desenvolvimento vem sendo lento em demasia. E não nos restam dúvidas de que isso é altamente prejudicial para as instituições e para o próprio sistema de comunicação, pois a linguagem jurídica representa um sistema organizacional vinculado a um sistema de normas.

\section{Linguagem opaca}

A linguagem forense é considerada por alguns linguistas como opaca por não interagir com a sociedade, que a qualifica como uma forma da língua repleta de arcaísmos, peculiaridades, vocábulos exageradamente herméticos e preciosismos vazios de significação. 
Mesmo que Direito e linguagem formem um par indissociável, não é fácil aceitar que a linguagem seja um elemento que distancie o cidadão comum do Direito. E esse distanciamento vem ocorrendo há tempos. Juristas vêm discutindo sobre o desconhecimento do conteúdo das normas jurídicas pelo homem médio, e esse desconhecimento é o tema tratado pelo jurisconsulto argentino Cárcova (1998, p. 14, grifo do autor), em sua obra "A Opacidade do Direito", na qual demonstra que

[...] entre o Direito e o seu destinatário, existe uma barreira "opaca" que os distancia, impossibilitando aquele último de absorver do primeiro os seus conteúdos e sentidos, entender os seus processos e instrumentos, tornando-o, por isso, incapaz de dele se beneficiar como seria esperado. Existe, pois, uma opacidade do jurídico.

O pior é que esse fato não seja considerado relevante por muitos dos envolvidos na elaboração das normas jurídicas. O cidadão comum pode até mesmo conhecê-las, mas não as compreende, não as utiliza como fonte de consulta quando necessário. Segundo John Rawls (2000) em sua obra "O liberalismo político", todos os cidadãos são livres e iguais, e também é necessário reconhecer e ratificar que a linguagem deve ser acessível e compreensível, de modo geral, a todos que dela procuram beneficiar-se.

Presumir que tais normas sejam do conhecimento de toda a sociedade também é objeto de questionamentos. E existe fundamento nisso, visto que é praticamente impossível conceber, a qualquer indivíduo, seja ele operador do Direito ou não, que todos de uma dada comunidade conheçam todas as referidas normas. Nas palavras do constitucionalista argentino Gérman Bidart Campos (apud CÁRCOVA, 1998, p. 37),

Nossa sociedade está inundada de normas de toda classe, de toda hierarquia, até da mais inferior. Somente a repetida estupidez de que, por uma presunção juris et de jure, as leis são conhecidas por todos, pode colaborar para a miopia da aplicação rígida e fria do axioma. Ora, a realidade nos diz que não são conhecidas por ninguém ou que o são por muito poucos.

Outro autor que também questiona a presunção acima citada é o ilustre jurista Eugênio Raúl
Zaffaroni (1987 apud SOUZA, 2003), quando afirma que compreender uma norma não implica só conhecê-la. O conhecimento é um grau inferior à compreensão. Já o francês André Jean Arnaud (apud SOUZA, 2003), doutor em Direito, questiona a real necessidade de se usar uma linguagem jurídica obscura e, muitas vezes, ininteligível para o leigo. Para ele, seria mesmo uma necessidade ou uma atitude premeditada?

De acordo com o sociólogo Henri Lévy-Bruhl, há ainda uma doutrina no Direito que, mesmo nos dias de hoje, defende o caráter estável e perpétuo das normas jurídicas. $\mathrm{O}$ autor discorda dessa afirmação (assim como a autora deste artigo), enfatizando que:

[...] se o direito emana do grupo social, não poderia ter mais estabilidade que esse mesmo grupo. Ora, um agrupamento humano não é senão uma reunião mais ou menos natural, voluntária ou fortuita, de indivíduos de sexo e idades diferentes, grupo que nunca permanece semelhante a si mesmo, uma vez que os elementos de que se compõe modificam-se a todo instante pelo efeito do tempo [...] Como o Direito, sendo a expressão da vontade de um grupo, poderia ser imutável, enquanto o grupo modifica-se constantemente? (LÉVY-BRUHL, 1988 apud SOUZA, 2003, p. 29).

O que se defende neste artigo é a importância da inteligibilidade textual. Numa perspectiva linguística e não jurídica demonstra-se que é possível a elaboração de textos forenses com linguagem clara, precisa e concisa, livre do verniz erudito e do preciosismo ainda tão cultuados por muitos da área jurídica, sem que se ignorem o aspecto formal da língua e o vocabulário técnico dessa área, com o intuito de melhorar substancialmente a relação entre o homem médio e o Direito.

\section{A linguagem jurídica na universidade}

O operador do Direito tem a responsabilidade social de aplicar a linguagem técnica forense de maneira eficiente. Para que isso ocorra, deve aprender a utilizá-la corretamente já no seio da Universidade, visto que esta, conforme exigido nas Diretrizes Curriculares do Curso de Direito, elaboradas a partir da Lei de Diretrizes e Bases da Educação Nacional (Lei $\mathrm{n}^{\circ}$. 9.394/96), com indicações fornecidas pelo Parecer $n^{\circ} .776 / 97$, da Câmara de Educação Superior 
(CES), tem a obrigação moral de formar cidadãos críticos e conscientes:

O perfil desejado do formando de Direito repousa em uma sólida formação geral e humanística, com capacidade de análise e articulação de conceitos e argumentos, de interpretação e valoração dos fenômenos jurídico-sociais, aliada a uma postura reflexiva e visão crítica que fomente a capacidade de trabalho em equipe, favoreça a aptidão para a aprendizagem autônoma e dinâmica, além da qualificação para a vida, o trabalho e o desenvolvimento da cidadania. (BRASIL, 2000, p. 3).

\section{Considerações finais}

Segundo o professor Luís Roberto Barroso (2007), "O mundo do Direito é o mundo da linguagem, falada e escrita". Em qualquer meio de manifestação nessa área o texto se faz presente, com o objetivo de persuadir e convencer seu receptor. É fundamental que o profissional do Direito conheça e domine o uso da palavra, sua ferramenta básica de trabalho, indispensável para a sua vida profissional e para a garantia da cidadania.

Entretanto, a escrita jurídica deve ser simples, objetiva, sem pedantismos e exercícios de virtuosismos, enfim, nunca uma demonstração de conhecimento restrito a poucas pessoas, uma apresentação da exuberância intelectual de seu autor. Sua eficácia está na escolha e utilização de palavras precisas: escrever pouco, mas com a noção exata do que se quer dizer.

A diretriz contemporânea é a simplicidade na elaboração de textos jurídicos. Mas isso não significa pobreza de vocabulário nem a supressão de informações necessárias ao caso. Há leis de legilibidade para as palavras e a redundância e a ambiguidade são pecados que devem ser evitados. Quanto ao vocabulário jurídico, é requisito indispensável para que as ideias do texto sejam apresentadas de forma adequada, com precisão de significado. Por isso, esse vocabulário deve ser simples, embora formal; técnico, mas sem exageros. O excesso de linguagem técnica revela superficialidade, ao contrário de demonstrar competência de quem escreve.

Além do mais, não podemos nos esquecer que um texto jurídico deve ser eficaz, para que possa atingir seu objetivo. Mas deve ser conciso, pois ao manter um texto longo, o requerente corre o risco de obter o efeito mais indesejável do mundo jurídico: ter a sua mensagem desprezada pelo destinatário.

Nossa sociedade necessita que a linguagem utilizada no sistema jurídico seja clara, objetiva e mais acessível à população, a fim de que possa atender aos anseios desta, proporcionar rapidez e eficácia nos trâmites. Uma escrita prolixa e excessivamente rebuscada afeta a prestação jurisdicional. Leis são criadas para orientar a vida em sociedade e devem ser observadas, respeitadas e aplicadas por todos.

Diante do exposto, ressalta-se que a simplificação da linguagem jurídica é aconselhável, trará benefícios a todos os envolvidos e irá aproximar esse tipo de linguagem à população. Assim, ela passa a ser um instrumento fundamental para a compreensão do funcionamento e da atuação do Poder Judiciário como um todo.

O principal foco em tal questão é conhecer o ponto de equilíbrio entre simplicidade e precisão. Termos técnicos devem ser mantidos, pois têm significados próprios. É isso que recomendam não somente os bons autores, mas também o próprio bom senso.

Em resumo, o operador do Direito que redige de maneira correta, que expõe de maneira harmoniosa suas teses, com clareza, coerência e objetividade, comunica-se bem, atinge sua meta. Esse profissional contribui para o bom andamento e o acesso à Justiça. Faz Justiça.

\section{Referências}

ARISTÓTELES; HORÁCIO; LONGINO. A poética clássica. Tradução direta do grego e do latim de Jaime Bruna. 13 ed. São Paulo: Cultrix, 2007.

ARRUDÃO, Bias. O juridiquês no banco dos réus. Revista Língua Portuguesa, São Paulo, ano 1, n. 2, p. 18-23, jun/dez. 2007.

ASSIS, Machado de. Instinto de Nacionalidade. In: Obra completa. Rio de Janeiro: Agullar, 1997. (Publicado originalmente em Novo Mundo, 24 março de 1873).

ASSOCIAÇÃO DOS MAGISTRADOS BRASILEIROS. Campanha para a Simplificação da Linguagem Jurídica. Disponível em: $<$ http://www.amb.com.br/portal/juridiques/book_premiados.pdf $>$. Acesso em: 10 out. 2011. 
BAKHTIN, Mikhail. Estética da criação verbal. São Paulo: Martins Fontes, 1979.

BARROSO, Luis Roberto. O direito, as emoções e as palavras. 12 fev. 2007. Disponível em: < http://www. migalhas.com.br/dePeso/16,MI35437,71043-O+direito + as+emocoes+e+as+palavras $>$. Acesso em: 20 set 2011.

BECHARA, Evanildo. Moderna gramática portuguesa: atualizada pelo novo acordo ortográfico. 37. ed. Rio de Janeiro: Lucerna, 2009.

BIDERMAN, Maria Tereza C. Teoria linguística: leitura e crítica. 2. ed. São Paulo: Martins Fontes, 2001.

BOBBIO, Norberto. O positivismo jurídico: lições de filosofia do direito. Compiladas por Nello Morra; tradução e notas por Marcio Pugliesi, Edson Bini, Carlos E. Rodrigues. São Paulo: Ícone, 1999.

BORGES JUNIOR, Fernando Luiz de O. Repensando a linguagem jurídica. Disponível em: $<$ http://www.amb.com.br/portal/juridiques/ RepensandoaLinguagemJurididica.doc $>$. Acesso em: 11 out. 2011.

BRASIL. MINISTÉRIO DA EDUCAÇÃO. Secretaria de Educação Superior. Comissão de Especialistas de Ensino de Direito [CEED]. Comissão de consultores. Diretrizes curriculares do curso de direito. Brasília, 13 e 14 jul. 2000. Disponível em: $<$ http://portal.mec.gov.br/sesu/ arquivos/pdf/dir_dire.pdf $>$. Acesso em: 24 set. 2011.

CAMPELLINI, Marília. Campanha pode extinguir linguagem rebuscada nos meios jurídicos. 15 abr. 2005. Disponível em: http://www.tj.ms.gov.br/noticias/ materia.php?cod=6766. Acesso em: 25 set. 2011.

CÁRCOVA, Carlos Maria. A opacidade do direito. Tradução: Edílson Alkmim Cunha. São Paulo: LTr, 1998.

CARVALHO; Paulo César de. Discurso em julgamento. Revista Discutindo Língua Portuguesa, São Paulo, ano I, n. 3, p.46-9, 2007.

FETZNER, Néli Luiza. A linguagem jurídica à luz do século XXI. In: FETZNER, Néli Luiza Cavalieri; PALADINO, Valquiria da Cunha (Org.). Argumentação jurídica: teoria e prática. Rio de janeiro: Freitas Bastos, 2006. p. 1-10.

FREITAS, Fernanda. A simplificação da linguagem jurídica como prática significativa de leitura: uma análise de sentenças forenses da comarca de campina Grande - PB no contexto do letramento. In: ENCONTRO NACIONAL DE LETRAMENTO ENALEF, 2008, Anais... João Pessoa, 2008.
GERMANO, Alexandre Moreira. Técnica de redação forense. São Paulo: Tribunal de Justiça do Estado de São Paulo, 2005.

GANDHI, Mohandas Karamchand. Frases e Pensamentos de Mahatma Gandhi. Disponível em: $<$ http://kdfrases.com/autor/mahatma-gandhi/20>. Acesso em: 13 out. 2011.

GNERRE, Maurizio. Linguagem, escrita e poder. 4. ed. São Paulo: Martins Fontes, 1998.

GOLD, Miriam; SEGAL, Marcelo. Português instrumental para cursos de direito: como elaborar textos jurídicos. São Paulo: Pearson Prentice Hall, 2008.

GONÇALVES, Rodrigo Tadeu. Humboldt e o Relativismo Linguístico. Estudos Linguísticos, Campinas, n. 35, p. 1700-1709, 2006. Disponível em: < http://www.gel. org.br/estudoslinguisticos/edicoesanteriores/4publicaestudos-2006/sistema06/1038.pdf $>$. Acesso em: 12 out 2011.

HUGO, Victor Marie. O facto e o direito. Disponível em: $\quad<$ http://www.citador.pt/textos/o-facto-e-o-direitovictor-marie-hugo >. Acesso em: 10 out. 2011.

KASPARY, Alberto J. Linguagem do direito. 2003. Disponível em: <http://dc439.4shared.com/doc/_xmoM4pj/ preview.html>. Acesso em: 13 out. 2011.

KOHEM, Roberto Lubianca. A opção por uma linguagem jurídica descomplicada. Administração da Justiça: Revista online. 20 set. 2011. Disponível em: <http:// www.ibrajus.org.br/revista/artigo.asp?idArtigo $=225>$. Acesso em: 15 out. 2011.

LIMA, Raimundo Ferreira de. A simplificação da linguagem jurídica como forma de possibilitar um maior e melhor acesso à justiça pelos cidadãos de baixa instrução. Disponível em: <http://www.cesrei. com.br/ojs/index.php/orbis/article/viewFile/21/16>. Acesso em: 11 out. 2011.

MACIEL, Roger Luiz. Linguagem jurídica: é difícil escrever direito?. Jus Navigandi, Teresina, ano 12, n. 1478, 19 jul. 2007. Disponível em: <http://jus.com.br/ revista/texto/10169>. Acesso em: 26 out. 2012.

MAIA, Márcio Barbosa. Falar difícil: Rui Barbosa, o ladrão de galinhas e o juridiquês. 23 maio, 2010. Disponível em: <http://www.conjur.com.br/2010-mai-23/ rui-barbosa-ladrao-galinhas-juridiques-decano-unb $>$. Acesso em: 11 out. 2011.

MEIRELLES, Cecília. Romance LIII ou Das palavras aéreas. In: Obra Poética. 3. ed. Rio de Janeiro: Nova Aguilar, 1987. Disponível em: <http://www. algumapoesia.com.br/poesia3/poesianet278.htm> Acesso em: 11 out. 2011. 
MENDONÇA, Neide R. de Souza. Desburocratização linguística: como simplificar textos administrativos. São Paulo: Pioneira, 1987.

MELLINKOFF, David. The language of the law. Boston: Resource Publications, 2004.

MOREIRA, Nedriane Scaratti et al. Linguagem jurídica: termos técnicos e juridiquês. UNESC\&Ciência-ACSA, Joaçaba, v.1, n.2, p. 139-46, jul./dez. 2010. Disponível em: <http://editora.unoesc.edu.br/index.php/acsa/article/ view/193/pdf_89>. Acesso em: 11 out. 2011.

MOREIRA, José Carlos Barbosa. A linguagem forense. In: Temas de direito processual civil. São Paulo: Saraiva, 2001.

NASCIMENTO, Edmundo Dantés. Linguagem forense: a língua portuguesa aplicada à linguagem do foro. 12. ed. rev.e atual., São Paulo: Saraiva, 2010.

NUNES, Rizzatto. Manual de introdução ao estudo do direito. São Paulo: Saraiva, 2006.

OLIVEIRA, Alexandre Vidigal de. Processo virtual e morosidade real. Administração da Justiça: Revista online. 24 mar. 2008. Disponível em: <http://www. ibrajus.org.br/revista/artigo.asp?idArtigo $=57>$. Acesso em: 10 out. 2011.

PERELMAN, Chaim; TYTECA, Lucie. Tratado da argumentação: a nova retórica. São Paulo: Martins Fontes, 2005.

PETRI, Maria José Constantino. Manual de linguagem jurídica. São Paulo: Saraiva, 2008.

PIZZINGA, Rodolfo Domenico. O pensamento do ultimo criador de sistemas filosóficos: Hegel. (Monografia pública, 2008). Disponível em: <http:// svmmvmbonvm.org/hegel.pdf $>$. Acesso em: 11 out. 2011.

RAWLS, John. Liberalismo político. Tradução de Dinah de Abreu Azevedo. Revisão de tradução de Álvaro de Vita. 2. ed. São Paulo: Ática, 2000.

REIS, André. Linguagem jurídica: simplicidade e foco. 16 dez. 2009. Disponível em: <http://www. recantodasletras.com.br/textosjuridicos/1981741>. Acesso em: 10 out. 2011.

SCHNAID, David. Filosofia do Direito e Interpretação. Londrina: UEL, 1998.

SALGADO, Eduardo. O fim do português. Veja, São Paulo, Edição 1.643, ano 33, n. 14, p. 11-5, abr. 2000. Disponível em: $<$ http://veja.abril.com.br/acervodigital/ home.aspx>. Acesso em: 12 out. 2011.
SIEGEL, Alan. Let's simplify legal jargon! (Filmed Feb 2010, Talk. In Less Than 6 Minute). Available in: $<$ http:// www.ted.com/talks/alan_siegel_let_s_simplify_ legal jargon.html >. Access: $1 \overline{1}$ out. 2011.

SILVA, Oscar José de Plácido e. Vocabulário jurídico. 18. ed. Rio de Janeiro: Forense, 2001.

SOARES, Luiz Eduardo. A ética e o intelectual no século XXI ou a arte de cultivar desertos privados. In: O desafio ético. Rio de Janeiro: Garamond, 2000.

SOUZA, Anderson Freire de. A linguagem no direito. $p$. 24-36. Disponível em <http://www.facape.br/anderson/ ied/A_linguagem_no_Direito.pdf $>$. Acesso em: 12 out. 2011.

STONE, Ronnie Frank Torres. Constituição para todos. Manaus: Valer Editora, 1998.

TRUBILHANO, Fábio. Linguagem jurídica e argumentação: teoria e prática. São Paulo: Atlas, 2010.

VON IHERING, Rudolf. O espírito do direito romano: nas diversas fases de seu desenvolvimento. Tradução de Rafael Benaion. Rio de Janeiro: Alba, 1943.

XAVIER, Ronaldo Caldeira. Português no direito. 15. ed., Rio de Janeiro: Forense, 1997.

ZILBERKNOP, L. S.; MARTINS, D. S. Português Instrumental: de acordo com as normas da ABNT. 29. ed. São Paulo: Atlas, 2010.

Data de submissão: 27/09/2012

Data de aceite: $31 / 10 / 2012$ 